\title{
The spectrum of self inflicted injuries managed at a major trauma centre in South Africa
}

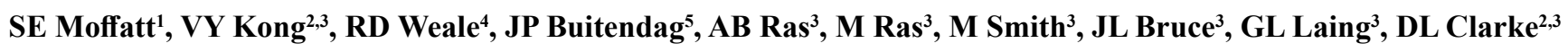 \\ ${ }^{1}$ Department of Surgery, University Hospitals Coventry and Warwickshire NHS Trust, Coventry, United Kingdom \\ ${ }^{2}$ Department of Surgery, University of the Witwatersrand, Johannesburg, South Africa \\ ${ }^{3}$ Department of Surgery, University of KwaZulu Natal, Durban, South Africa \\ ${ }^{4}$ Department of Surgery, North West Deanery, Manchester, United Kingdom \\ ${ }^{5}$ Department of Surgery, Tygerberg Hospital, Stellenbosch University, Cape Town, South Africa
}

Corresponding author: Victor Kong (victorywkong@yahoo.com)

\begin{abstract}
Background: Self-harm behaviour is a major public health problem that is commonly underreported. This study reviews the spectrum of these self inflicted injuries managed by a major trauma centre in South Africa.

Methods: A retrospective review of the regional trauma registry was undertaken over a five-year period from December 2012 to December 2017 at the Pietermaritzburg Metropolitan Trauma Service (PMTS) in South Africa. All patients who were admitted after they had sustained an injury as a result of self-harm were included.

Results: During the five-year study period, a total of 179 patients were included. The mean age was 29 years (SD12) and there were 139 (77\%) males and 40 (23\%) females. Of these, 16 had a previously established psychiatric diagnosis and two had a prior history of having sustained self-harm. The previously diagnosed psychiatric illnesses included mood dysphoria disorders (5), schizophrenia (3), substance abuse and dependency (1), anti-social personality disorder (1) and unspecified (6). The mechanism was penetrating trauma in 47 (26\%). The penetrating mechanisms included stab wounds (SW) in 33, gunshot wounds (GSW) in 10, broken glass in 2 and a single impalement. Blunt mechanisms accounted for the remaining $131(73 \%)$ injuries. The most common mechanism of blunt self-harm was hanging in 101 patients. This was followed by vehicular related trauma (8), jumping in front of a train (1) and jumping from a height (1). In 17 patients the exact mechanism of the blunt trauma was unclear. There was no statistical difference in the mechanism of injury between male and female patients. There were $38(28 \%)$ men and $9(23 \%)$ women who sustained a penetrating injury and there were 100 (72\%) male and $31(78 \%)$ female patients who had a blunt mechanism of injury. A total of 53 CT scans were obtained, 40 chest X-rays, 9 abdominal X-rays and 2 ultrasounds. There were 113 neck injuries, 68 head injuries, 24 abdominal injuries, 15 upper limb and 15 lower limb injuries and four facial injuries. A total of 32 operations were performed. These included laparotomy (14), neck exploration (5), tracheostomy (4). A total of 22 patients developed a complication.

Conclusion: Self-inflicted injury is not uncommon and frequently requires investigation and or surgical treatment. Patients who sustain such an injury constitute a distinct vulnerable group who are under researched. Future research on this vulnerable patient group is needed.
\end{abstract}

S Afr J Surg 2019;57(2)

http://dx.doi.org/10.17159/2078-5151/2019/v57n2a2897

\section{Introduction}

Trauma has long been recognised as a major public health problem in South Africa. ${ }^{1}$ Violent crime in particular has commanded much media attention at both the local and the international level. ${ }^{1}$ However, there are specific vulnerable groups within the overall trauma population, which have received much less attention. One such group of patients, is those who sustain self-inflicted trauma. ${ }^{2-9}$

Self-harm is a very broad term and there are many reasons why a patient may engage in self harm. These include major psychiatric illnesses such as psychosis and depression as well as psychological problems related to personality traits and to social stressors. There is a huge burden of psychiatric and psychological illness in South Africa that is often under reported. It is estimated that between 6000 and 8000 South Africans commit suicide each year. This translates to between 16 to 22 cases each day. In addition children and teenagers represent $33 \%$ of patients hospitalised after suicide attempts. ${ }^{2-9}$ Despite this, relatively little research has been undertaken locally to explore the presentation of deliberate self-harm 
within the South African context and the spectrum of injury encountered, as well as the management and clinical outcome of these patients, remains largely unknown. This study reviews the Pietermaritzburg Metropolitan Trauma Service (PMTS) experience with victims of self-inflicted wounds and goes on to describe the spectrum of these self-inflicted injuries as well as their management and outcome.

\section{Materials and Methods}

\section{Clinical Setting}

This study was undertaken at the Pietermaritzburg Metropolitan Trauma Service (PMTS), Pietermaritzburg, KwaZulu-Natal, South Africa. KwaZulu-Natal is located on the east coast of the country and has a population of over 11 million. Fifty per cent of the population live in the rural areas. The PMTS provides definitive trauma care to the city of Pietermaritzburg, the capital of Kwa-Zulu Natal (KZN) province. It is one of the largest trauma center in the province and also serves as the referral center for 19 rural hospitals within the province, with a total catchment population of over three million. Surgical staff maintain a digitized regional trauma registry for assessment and re-evaluation of outcomes. This system is known as the Hybrid Electronic Medical Registry (HEMR). Ethics approval to maintain this database has been granted by the Biomedical Research Ethics Committee (BREC) of the University of Kwa-Zulu Natal (BE221/13 and BE 207/09).

\section{The Study}

A retrospective review of the regional trauma registry was undertaken over a five-year period from December 2012 to December 2017. All patients who sustained any injury directly related to self-harm were included. Basic demographic descriptions were performed. The severity of injury was measured using the Abbreviated Injury Scale (AIS) to ensure consistency in grading and the Injury Severity Score (ISS) was used to grade patients with multiple injuries. Outcomes reviewed included the need for surgery, the type of surgery and the associated morbidity and mortality. Caustic ingestions were excluded from this analysis.

\section{Statistics}

\section{Results}

\section{Demographics and presenting physiology}

During the five-year study period, a total of 179 patients sustained self-harm and were managed by the PMTS. The mean age was 29 years (SD12) and there were 139 (77\%) males and $40(23 \%)$ females. Of these, 16 had a previously established psychiatric diagnosis and two had prior histories of having sustained self-harm. The previously diagnosed psychiatric illnesses included MDD (5), schizophrenia (3), substance abuse and dependency (1), anti-social personality disorder (1) and unspecified (6). In the patients who attempted to hang themselves, $60.9 \%$ had consumed alcohol just prior to the incident. There were 139 patients from the city of

\section{Table 1: Demographics}

\begin{tabular}{lc}
\hline Number & 179 \\
Total & $29(12)$ \\
Age (SD) & $139: 40$ \\
M:F & $139: 40$ \\
Urban:Rural & 16 \\
Known psychiatric history & 2 \\
Previous attempt & 23 \\
Injury time to admission (median hours) & \\
Psychiatric diagnosis & 5 \\
MDD & 3 \\
Schizophrenia & 1 \\
Addiction & 1 \\
Antisocial personality & 6 \\
Unknown &
\end{tabular}

\begin{tabular}{|c|c|c|c|}
\hline \multicolumn{2}{|c|}{ Mean physiology (SD) } & \multirow{2}{*}{$\begin{array}{c}\text { Mean value: } \\
\text { Male(SD): Female } \\
\text { (SD) } \\
87(23): 100(24)\end{array}$} & \multirow{2}{*}{$\begin{array}{l}\text { P value } \\
<0.005\end{array}$} \\
\hline HR & $90(24)$ & & \\
\hline SBP & $122(20)$ & 122(18): 121(23) & 0.8199 \\
\hline GCS & $13(4)$ & 13(4): 12(5) & 0.4275 \\
\hline Temp & $36.4(0.7)$ & $36.5(0.8): 36.4(0.6)$ & 0.9241 \\
\hline $\mathrm{pH}$ & $7.4(0.1)$ & $7.36(0.1): 7.35(0.1)$ & 0.6585 \\
\hline Lactate & $2.9(3.0)$ & $2.8(2.8): 3.0(3.7)$ & 0.7517 \\
\hline ICU & $18(10 \%)$ & $11(8 \%): 7(18 \%)$ & 0.0756 \\
\hline Died & $9(5 \%)$ & $6(4 \%): 3(8 \%)$ & 0.4168 \\
\hline
\end{tabular}

Pietermaritzburg and 40 from the rural areas of western KZN. Table 1 summarizes the demographics of the cohort. Table 2 summarizes the presenting physiology of the patient cohort.

\section{Mechanism}

The mechanism was penetrating trauma in $47(26 \%)$. The penetrating mechanisms included stab wounds (SW) in 33, gunshot wounds (GSW) in 10, broken glass in 2 and a single impalement. Figure 1 shows a self-inflicted wound of the neck and Figure 2 shows the CT scan of a suicide victim who attempted to shoot himself in the head. Blunt mechanisms accounted for the remaining 131 (73\%) injuries. The most common mechanism of blunt self-harm was hanging in 101 patients. This was followed by vehicular related trauma in (8), jumping in front of a train in (1) and jumping from a height in (1). In 17 patients, the exact mechanism of the blunt trauma was unclear. There was no statistical difference in 


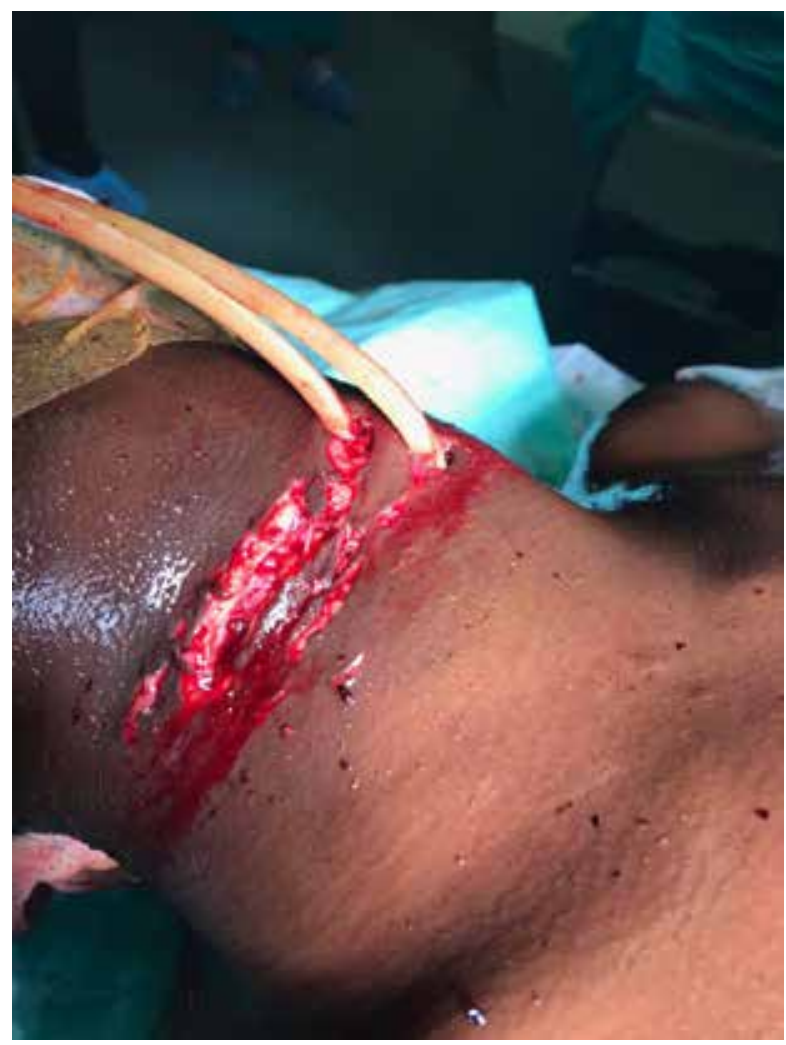

Figure 1. Self-inflicted neck wound

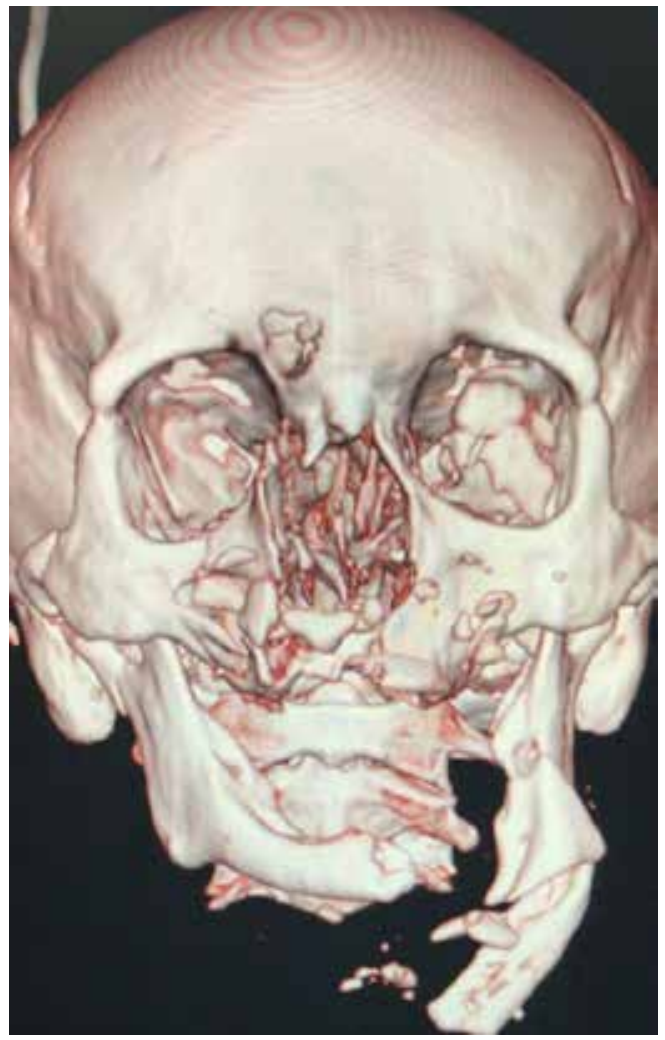

Figure 2. CT scan of an attempted suidice using a firearm
Table 3: Mechanism (p value calculated using chisquare test)

\begin{tabular}{lcccc}
\hline Penetrating & & $\begin{array}{c}\text { Male : } \\
\text { Female (n) }\end{array}$ & $\begin{array}{c}\text { Male : } \\
\text { Female (\%) }\end{array}$ & P value \\
\hline Total & 47 & $38: 9$ & $28: 23$ & 0.540 \\
SW & 33 & $28: 5$ & $20: 13$ & 0.272 \\
GSW & 10 & $8: 2$ & $6: 5$ & 0.855 \\
Glass & 3 & $1: 2$ & $1: 5$ & 0.0631 \\
Impalement & 1 & $1: 0$ & $1: 0$ & 1.00 \\
Blunt & & & & \\
Total & 131 & $100: 31$ & $72: 78$ & 0.484 \\
Hanging & 101 & $77: 24$ & $55: 60$ & 0.605 \\
PVA & 4 & $3: 1$ & $3: 3$ & 0.897 \\
MVA & 4 & $3: 1$ & $3: 3$ & 0.897 \\
$\quad$ Fall from & & & & \\
$\quad$ height & 4 & $3: 1$ & $3: 3$ & 0.897 \\
$\quad$ Train & 1 & $0: 1$ & $0: 3$ & 0.224 \\
Unknown & 17 & - & - &
\end{tabular}

\begin{tabular}{|c|c|c|c|}
\hline CT & & $0 \%)$ & \\
\hline CXR & & $2 \%)$ & \\
\hline AXR & & & \\
\hline USS & & $5 \%)$ & \\
\hline FAST & & $5 \%)$ & \\
\hline $\begin{array}{c}\text { Body region } \\
\text { injured }\end{array}$ & n (\%) & M : F (\%) & $\begin{array}{c}\text { Mean } \\
\text { AIS }\end{array}$ \\
\hline Neck & $113(63 \%)$ & $\begin{array}{l}\text { 89: } 24(\mathrm{n}) \\
\text { 64: } 60(\%)\end{array}$ & 2 \\
\hline Head & $68(38 \%)$ & $\begin{array}{l}\text { 44: } 24(\mathrm{n}) \\
32: 17(\%)\end{array}$ & 2 \\
\hline Abdomen & $24(13 \%)$ & $\begin{array}{c}\text { 17: } 7(\mathrm{n}) \\
12: 18(\%)\end{array}$ & 2 \\
\hline Upper limb & $15(8 \%)$ & $\begin{array}{l}\text { 10: } 5(\mathrm{n}) \\
\text { 7: } 13(\%)\end{array}$ & 2 \\
\hline Lower limb & $15(8 \%)$ & $\begin{array}{l}\text { 10: } 5(\mathrm{n}) \\
\text { 7: } 13(\%)\end{array}$ & 2 \\
\hline Face & $8(4 \%)$ & $\begin{array}{c}\text { 8: } 0 \\
\text { 6: } 0(\%)\end{array}$ & 2 \\
\hline
\end{tabular}




\begin{tabular}{lc} 
Table 5: Operative management and complications & \\
\hline Operative management & $\mathbf{3 2}$ \\
\hline Total & 14 \\
Laparotomies & 5 \\
Neck exploration & 1 \\
Complex facial reconstruction & 3 \\
Tracheostomy & 2 \\
PEG & 2 \\
Spinal surgery & 1 \\
Laparoscopy & 1 \\
Tendon repair & 1 \\
Fixation of fracture & 1 \\
Subclavian artery repair & 1 \\
Anterior abdominal wall repair & 1 \\
Complications & $\mathbf{2 2}$ \\
\hline Total & 7 \\
Neurological & 5 \\
Respiratory/Pneumonia & 2 \\
Renal & 1 \\
Cardiac & 5 \\
Abdominal & 2 \\
Wound & 1 \\
Other & 1 \\
\hline
\end{tabular}

the mechanism of injury between male and female patients. There were $38(28 \%)$ men and $9(23 \%)$ women who sustained a penetrating injury and there were $100(72 \%)$ male and 31 (78\%) female patients who had a blunt mechanism of injury. Table 3 summarizes the mechanisms of injury according to sex.

\section{Interventions}

A total of $53 \mathrm{CT}$ scans were obtained, 40 chest X-rays, 9 abdominal X-rays and 2 ultrasounds. Table 4 tabulates these investigations. There were 113 neck injuries, 68 head injuries, 24 abdominal injuries, 15 upper limb and 15 lower limb injuries and four facial injuries. A total of 32 operations were performed. These included laparotomy (14), neck exploration (5), and tracheostomy (4). The remainder are listed in Table 5. A total of 22 patients developed a complication. These are broken down in Table 5 . A total of $4.5 \%$ of patients required ICU admission and the overall mortality rate was $2.5 \%$. Figure 1 demonstrates a self-inflicted laceration of the neck in an acutely psychotic patient. This required a neck exploration and ligation of a severed internal jugular vein and reconstruction of the injured larynx. Figure 2 is the CT scan of a man who shot himself in the face. He survived the injury and required extensive reconstructive surgery.

\section{Multi-disciplinary team management}

All patients who are admitted following a self-inflicted injury are seen by the psychology department prior to discharge. A dedicated template is used to assess each patient and to clarify whether the incident is a true suicide attempt or a case of self-harm or self-mutilation. The patients are screened for substance abuse and for underlying organic depression or mental illness. The social work department investigates social stressors which may have precipitated the incidence. If these disciplines identify an underlying organic mental illness, then psychiatric input is obtained. The department of psychology follows these patients up as appropriate.

\section{Discussion}

Suicide and self-harm is a major global public health problem and is the tenth leading cause of death in the United States. In 2014, there were over seventy-six thousand suicide related deaths in that country. In certain vulnerable demographic groups the impact of suicide is even greater. Amongst the population aged 15 to 34 it is the second most common cause of death and in children aged 10 to 14 , the mortality rate from suicide is on a par with that from traffic accidents. It is estimated that over one million adults attempt suicide each year in the USA. ${ }^{10}$ The situation in South Africa is less well documented but the available evidence suggests that the situation is equally dire..$^{2-9}$ The crude rate of suicide in South Africa in 2010 was 12.2 per 100 000. Suicide was responsible for $8 \%$ of all deaths in South Africa and a 2013 paper by the South African Medical Research Council estimated that one in five adolescents have considered suicide. Mental illness and suicide are significant problems in South Africa and the resources to deal with this burden of disease are insufficient. The low incidence of previously diagnosed psychiatric illness reflects lack of access to state mental health services in the province. $^{2-9}$

This paper has documented the spectrum of self-inflicted injuries managed by a high volume trauma centre in a major city in South Africa. Self-inflicted injury is a predominantly a problem affecting young male patients less than thirty years of age. The commonest mechanism is blunt trauma (77\%) of which the single most frequent modality is attempted hanging. This is consistent with the findings of other researchers in this field. Jumping from a height and in front of a moving vehicle are less common modalities in patients who present alive to hospital. The incidence of penetrating mechanisms is much lower than blunt mechanisms. Access to weapons is a risk factor for male suicide and knives and firearms are readily available in South Africa and are frequently used in suicide attempts.

Self-harm related injuries place a significant burden on all departments in the hospital. They often require imaging and not infrequently require surgical treatment. The most common operations are laparotomies and neck explorations. Occasionally significant injuries require complex surgical reconstruction involving a number of sub-specialties. The man with the laceration to his neck (Figure 1) required complex reconstruction and a tracheostomy whilst the patient with the 
gunshot wound to his face (Figure 2) required complex plastic and maxillofacial surgery.

Once the injury has been treated then a multi-disciplinary treatment plan is needed. ${ }^{11-13}$ This will involve a psychological assessment to determine the intent of the self-harm incident. Does it represent a well-formed intention on the patient's part to end his/her life or is it merely an example of self-mutilation and not an actual suicide attempt. Social work assessment is needed to determine if there are major social stressors behind the incident. If there is evidence of organic mental illness, then psychiatric support is needed. Major psychotic episodes may require aggressive pharmacotherapy. The long-term outcome for these patients is unclear as the reported incidence of recidivism in suicide victims is high, however the surgical team's role in this therapeutic plan is limited and beyond the scope of this audit. ${ }^{11-13}$

The are major limitations to this study. The lack of mortuary data results in an under-estimation of the problem. Patients who die following a self-inflicted suicidal injury are taken directly to the medico-legal laboratory and are not recorded in our database. It is likely that jumps from a height, vehicle related injuries and cerebral GSW's will have a significant mortality rate which this study is unable to quantify. The fact that this report emanates from a referral center biases the sample, as rural patients with minor self-inflicted injuries will not be transferred to our center. In addition, this study has focused on self-inflicted wounds and has omitted other frequent modalities of self-harm such as caustic ingestion and poisons. If these two common mechanisms were to be included the incidence of suicide and self-harm would be significantly higher.

\section{Conclusion}

Self-inflicted injuries are not uncommon and frequently require investigation and or surgical treatment at our tertiary trauma service. Patients who sustain self-inflicted wounds constitute a distinct under researched vulnerable group. As such, particular emphasis should be placed on promoting future research on this cohort of patients.

\section{Conflicts of Interest}

The authors declare no conflicts of interest.

\section{Ethics}

Ethics approval was granted by the Biomedical Research Ethics Committee (BREC) of the University of Kwa-Zulu Natal (BE221/13 and BE 207/09).

\section{REFERENCES}

1. Lutge E, Moodley N, Tefera A, et al. A hospital based surveillance system to assess the burden of trauma in
KwaZulu-Natal Province South Africa. Injury. 2016;47:135-40. doi: 10.1016/j.injury.2015.08.020

2. Stark K, Joubert G, Struwig M, Pretorius M, van der Merwe N, Botha $\mathrm{H}$, et al. Suicide cases investigated at the state mortuary in Bloemfontein, 2003-2007. South African Family Practice. 2010;52(4):332-5. doi: 10.1080/20786204.2010.10874001

3. Pauw I. How to curb the increase in teen suicides. [Accessed 24/06/2009]. Available at: http:// www.health24.com/mind/ Mental_health_in_SA/ 1284-1301,26685.asp

4. Wasserman D, Cheng Q, Jiang G. Global suicide rates among young people aged 15-19. World Psychiatry. 2005;4:114-20.9.

5. Jack H, Wagner RG, Petersen I, et al. Closing the mental health treatment gap in South Africa: a review of costs and costeffectiveness. Glob Health Action. 2014;7:23431. Available at: http://www.ncbi.nlm.nih.gov/pmc/articles/PMC4038770/.

6. Khuzwayo N, Taylor M, Connolly C. High risk of suicide among high-school learners in uMgungundlovu District, KwaZulu-Natal Province, South Africa. South African Med J. 2018;108:517. doi: 10.7196/SAMJ.2018.v108i6.12843

7. National Institute of Mental Health. Mental Health Information $>$ Statistics. [Accessed 10 Sep 2018]. Available at: https://www. nimh.nih.gov/health/statistics/suicide.shtml

8. World Health Organisation. World Health Statistics data visualizations dashboard. [Accessed 9 Sep 2018]. Available at: http://apps.who.int/gho/data/node.sdg.3-4-data?lang=en

9. Shilubane HN, Ruiter RA, Van Den Borne B, et al. Suicide and related health risk behaviours among school learners in South Africa: Results from the 2002 and 2008 national youth risk behaviour surveys. BMC Public Health. 2013;13:1. doi: 10.1186/1471-2458-13-926

10. Rockett IRH, Lilly CL, Jia H, et al. Self-injury mortality in the United States in the early 21 st century a comparison with proximally ranked diseases. JAMA Psychiatry Published Online First: 2016. doi: 10.1001/jamapsychiatry.2016.1870

11. Pillay AL, Anthony L, Wassenaar DR. Non-fatal suicidal behaviour in South Africa: a study of patients of African descent. Journal of Psychology in Africa. 1 Jan 2001;11(1):7387.

12. Bantjes J. 'Don't push me aside, Doctor': Suicide attempters talk about their support needs, service delivery and suicide prevention in South Africa. Heal Psychol Open. 2017;4:2055102917726202. doi: 10.1177/2055102917726202

13. Pillay AL, Wassenaar DR, Kramers AL. Attendance at psychological consultations following non-fatal suicidal behaviour: An ethical dilemma. South African Journal of Psychology. Sep 2004;34(3):350-63. 